\title{
Uhl's anomaly: perspective of fetal echocardiography and histopathological correlation
}

\author{
Damon B. Dixon, ${ }^{1}$ Shannon M. Mackey-Bojack, ${ }^{2}$ Shanthi Sivanandam ${ }^{1}$ \\ ${ }^{1}$ Department of Pediatrics, Division of Cardiology, University of Minnesota; ${ }^{2}$ Jesse E. Edwards Registry of Cardiovascular \\ Disease, Minneapolis, Minnesota, United States of America
}

\begin{abstract}
We report a case of Uhl's anomaly imaged at 19 weeks of gestation by fetal echocardiography with pathological confirmation by anatomical gross heart specimen and tissue histology. Uhl's anomaly of the right ventricle is a rare cardiac disorder with isolated right ventricular enlargement with almost complete absence of the right ventricular myocardium.
\end{abstract}

Keywords: Uhl's anomaly; fetal imaging; histopathology

Received: 28 October 2015; Accepted: 16 July 2016; First published online: 30 August 2016

\section{Case report}

Uhl's anomaly is a rare form of $\mathrm{CHD}$, characterised by almost complete absence of the right ventricular myocardium. ${ }^{1}$ William Osler $^{2}$ in 1905 described the "parchment heart"; however, the anomaly was named after Henry Uhl who reported the first case in 1952. Pathogenesis was previously described as a congenital developmental failure in human embryogenesis. More recent publications have described a mechanism of triggered apoptotic pathways or failure to protect from apoptosis. ${ }^{3}$ The Wnt pathway has been proposed as a possible mechanism, where the Wnt ligands fail to suppress apoptosis of the myocytes, thus leading to complete loss of the right ventricular myocardium. Wnt/beta-catenin signalling is required for proliferation and expansion of several specified cardiogenic progenitors; however, for terminal differentiation, Wnt/beta-catenin signalling has to become low. ${ }^{4-6}$ The prognosis of Uhl's anomaly is poor.

We report a case of Uhl's anomaly imaged at 19 weeks of gestation by fetal echocardiography with pathological confirmation by anatomical gross heart specimen and tissue histology. A 25-year-old woman gravida 1 , para 0 - was referred for an abnormal cardiac finding on an obstetric ultrasound at 18 weeks of

Correspondence to: S. Sivanandam, MD, Department of Pediatrics, Division of Cardiology, University of Minnesota, 5th Floor East Building, Room MB551, 2450 Riverside Avenue, Minneapolis, MN 55454, United States of America. Tel: +1612626 2755; Fax: +16126262467; E-mail: silv0099@umn.edu gestation. The ultrasound demonstrated enlargement of the right ventricle and concerns of a cystic lesion in the right ventricle. Differential diagnosis included Ebstein's anomaly, Uhl's anomaly, congenital right ventricular aneurysm, and arrhythmogenic right ventricular dysplasia. The patient had no significant past medical history and denied any exposure to teratogens during pregnancy or any recent viral illnesses.

A fetal echocardiogram performed at 19 weeks of gestation demonstrated a thin-walled "out-pouching" of the right ventricular free wall that extended from the apex to the base of the heart. The cardio-thoracic ratio was $70 \%$, representing cardiomegaly. The out-pouching measured $2.7 \times 1.7 \mathrm{~mm}$, without apical trabeculations or hypokinesis. There was no evidence of clot or thrombus formation seen within the out-pouching. There was right atrial enlargement, and the tricuspid valve appeared normally formed. The tricuspid valve annulus size and the pulmonary valve annulus size were normal. The tricuspid valve was not dysplastic, and there was no apical displacement of the annulus, ruling out Ebstein's anomaly. There was severe tricuspid and mild pulmonary regurgitation by color Doppler technique. There was normal Doppler flow across the pulmonary valve. There was a small circumferential pericardial effusion. The heart rate was regular with preserved left ventricular systolic function (Fig 1a) (Supplementary video 1 and 2). A fetal MRI depicted the heart positioned in the left hemi-thorax with cardiomegaly. There was right ventricular 

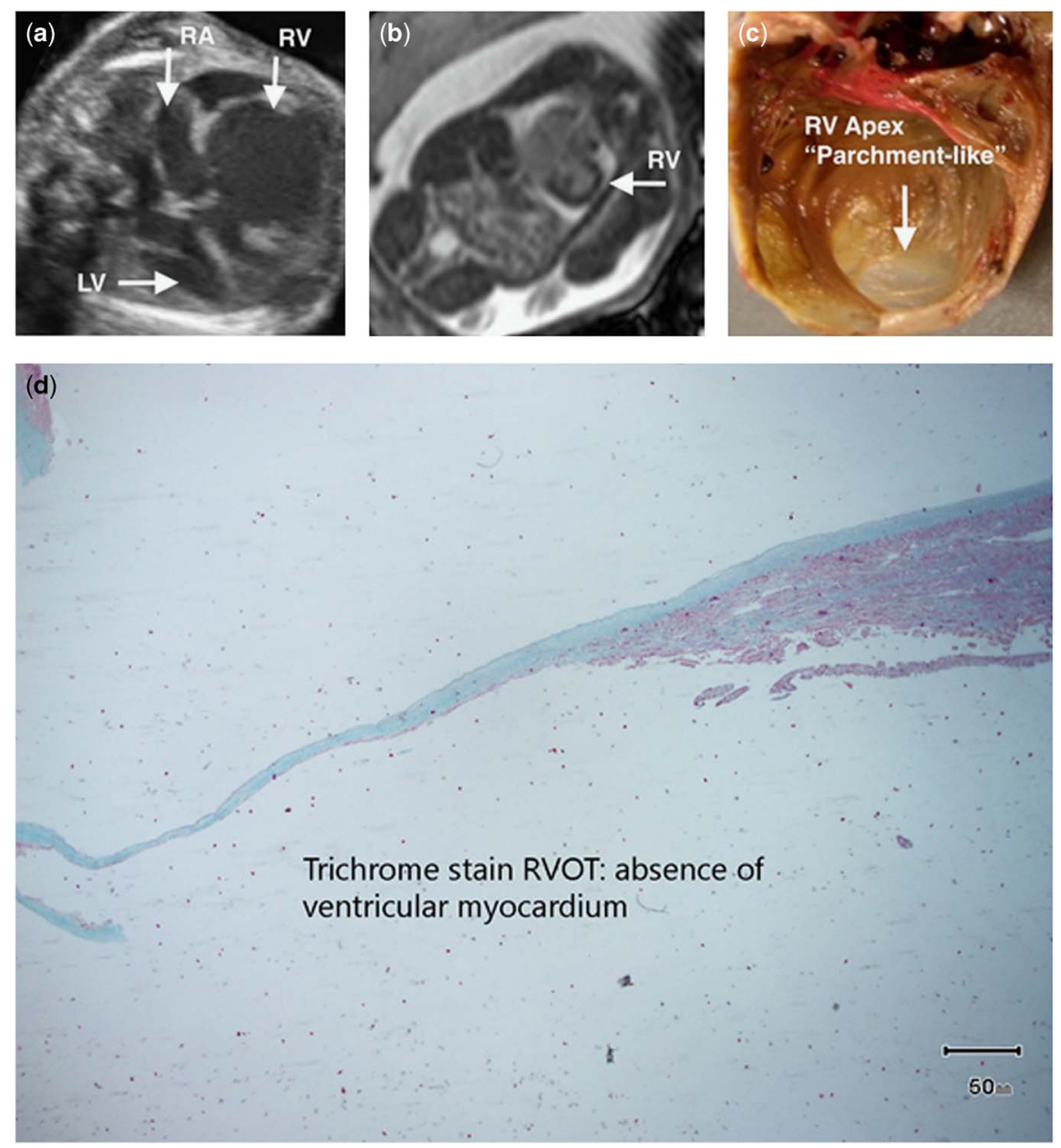

Figure 1 .

(a) Supplementary video 1 and 2: fetal echocardiogram at 19 weeks of gestation shows marked dilation of the right ventricle (RV), extending from the base to the apex. Small pericardial effusion and right atrial enlargement (RA). (b) Fetal MRI shows right ventricular enlargement that measured $2.2 \times 2.2 \times 1.7 \mathrm{~cm}$. (c) Gross specimen shows the right atrium, tricuspid valve, and right ventricle $(R V)$. The right ventricle is markedly dilated with almost complete absence of right ventricular myocardium. Parchment-like appearance of the right ventricle. (d) Trichome stain of the right ventricular outflow tract (RVOT) demonstrating the absence of apical myocardium and the presence of myocardium in the infundibulum. $L V=$ left ventricle.

enlargement measuring $2.2 \times 2.2 \times 1.7 \mathrm{~cm}$ with a paucity of apical trabeculations and absence of fibrofatty infiltration, ruling out arrhythmogenic right ventricular dysplasia (Fig 1b). There were no extracardiac anomalies described.

Intrauterine death occurred at 26 weeks of gestation, likely due to progressive hydrops (obstetric scan) from right heart failure or arrhythmias. A cardiac autopsy revealed a significantly enlarged heart. The gross specimen had an abnormal shape and consisted mainly of a dilated, thin-walled right ventricle (Fig 1c). All arterial and venous connections were normal. The tricuspid valve had three definable leaflets with poorly formed chordae tendinae that inserted into the right ventricular wall and poorly formed anterior papillary muscle. The right ventricle was markedly dilated with almost complete absence of the trabecular and compact myocardium, which was most prominent at the apex. The infundibulum contained myocardium, and the ventricular septum was intact. The pulmonary valve was tricuspid and normally formed, as was the mitral valve and left ventricle. Histological examination with trichome staining of the right ventricular outflow tract demonstrated the absence of apical myocardium and the presence of myocardium in the infundibulum (Fig 1d). The typical histological findings are transparent right ventricular free wall due to an apposition of the endocardium and epicardium without intervening myocardium, infiltration, or inflammation. ${ }^{5}$

Uhl's anomaly is a difficult prenatal diagnosis that has been reported. ${ }^{7,8}$ Bessinger et al reported a fetus at 24 weeks of gestation with marked right heart enlargement and pulmonary atresia - a possible variant of Ebstein's anomaly. The infant was born at term, and 
died a few hours after birth; at autopsy, the right ventricle measured $0.05 \mathrm{~cm}$ at its greatest thickness, markedly dilated and paper thin. ${ }^{9}$ Roberts et al reported a case of Uhl's anomaly mimicking Ebstein's anomaly at 18 weeks of gestation, based on sonographic findings in 1995, and the patient elected to terminate the pregnancy at 21 weeks; the diagnosis was confirmed at autopsy. ${ }^{10}$ Calabro et al reported a case of Uhl'a anomaly diagnosed at 31 weeks of gestation; the infant was born at 37 weeks and had right heart enlargement with ventricular kinesis and right ventricular thrombi, which was medically managed and the patient had improved ventricular function and survival. ${ }^{11}$ Kato et al in 2015 presented a fetal echocardiogram at 26 weeks of gestation with enlarged right ventricle, severe tricuspid and pulmonary regurgitation, and ruptured ventricular septal aneurysm, resulting in a circular shunt. At 36 weeks, based on the presence of a thin ventricular wall and the absence of apical trabeculation, a diagnosis of Uhl's anomaly was made. The neonate underwent main pulmonary artery ligation to eliminate the circular shunt and subsequently underwent pulmonary arteryto-aorta shunt. The child is awaiting a staged Fontan operation involving a bidirectional Glenn procedure. ${ }^{12}$

On the other hand, the advancement of fetal echocardiography and complementary advance MRI has strengthened the accuracy of diagnosis of this rare cardiac anomaly. Our case report is unique for fetal echocardiogram, autopsy, and histology findings as well as correlation. Further assessment of genetic analysis will additionally delineate the mechanism of apoptosis of the right ventricular myocytes.

\section{Acknowledgements}

None.

\section{Financial Support}

This research received no specific grant from any funding agency, commercial or not-for-profit sectors.

\section{Conflicts of Interest}

None.

\section{Supplementary material}

To view supplementary material for this article, please visit http://dx.doi.org/10.1017/S1047951116001232

\section{References}

1. Uhl HSM. A previously undescribed congenital formation of the heart: almost total absence of the myocardium of the right ventricle. Bull Johns Hopkins Hosp 1952; 91: 197-205.

2. Osler WM. The Principles and Practice of Medicine, 6th edn. D. Appleton, New York, 1905; 280.

3. James TN. Complete heart block and fatal right ventricular failure in an infant. Circulation 1996; 93: 1588-1600.

4. Pamuru PR, Dokuparthi MV, Remersu S, Calambur N, Nallari P. Comparison of Uhl's anomaly, right ventricular outflow tract ventricular tachycardia (RVOT VT) \& arrhythmogenic right ventricular dysplasia/cardiomyopathy (ARVD/C) with an insight into genetics of ARVD/C. Indian J Med Res 2010; 131: $35-45$.

5. Lisovsky M, Itoh K, Sokol S. Frizzled receptors activate a novel JNK-dependent pathway that may lead to apoptosis. Curr Biol 2002; 12: 53-58.

6. Gessert S, Kuhl M. The multiple phases and faces of wnt signaling during cardiac differentiation and development. Circ Res 2010; 107: 186-199.

7. Kim MJ, Bae JY, Seong WJ. A case of prenatally diagnosed Uhl's anomaly. Clin Exp Obstet Gynecol 2015; 42: 234-236.

8. Philip S, Bharati S, Cherian KM, Bharati S. Prenatal diagnosis of Uhl anomaly with autopsy correlation. AJP Rep 2016; 6: e91-e95.

9. Wager GP, Couser RJ, Edwards OP, Gmach C, Bessinger B Jr. Antenatal ultrasound findings in a case of Uhl's anomaly. Am J Perinatol 1988; 5: 164-167.

10. Benson CB, Brown DL, Roberts DJ. Uhl's anomaly of the heart mimicking Ebstein's anomaly in utero. J Ultrasound Med 1995; 14: 781-783.

11. Cardaropoli D, Russo MG, Paladini D, et al. Prenatal echocardiography in a case of Uhl's anomaly. Ultrasound Obstet Gynecol 2006; 27: 713-714.

12. Uozumi T, Fujita $\mathrm{Y}$, Tsukimori $\mathrm{K}$, et al. Prenatal ultrasonographic diagnosis of Uhl anomaly. Case Report Perinat Med 2015; 4: $57-60$. 